\section{How to protect general practice from child protection}

I am grateful to Danny Lang for providing a reading list to help me in struggling to cope with my role as a GP in child protection. ${ }^{1}$ I suspect that his safeguarding colleague Janice Allister would suggest more robust measures of support to help me to overcome what she regards as my "cynical denial of what is a very real problem'. ${ }^{2}$ Both Dr Lang's readings and Dr Allister's exhortations confirm the very real problems I sought to highlight in the column that has so upset them: the presumption that the box-ticking bureaucracy currently dominating child protection in general practice is effective in preventing abuse or neglect, and the apparent indifference of the safeguarding zealots to the adverse consequences of further medical intrusion in intimate relationships. ${ }^{3}$

I do not intend to revisit the child protection controversy here lthough I note in passing that if we accept Dr Allister's judgement, that to hold a case conference in the absence of a GP would be 'farcical', then the majority of case conferences that are taking place must be so described). I would, however, like to respond to Dr Allister's challenge to what she found 'most disturbed' her in my article: my contention that GPs should not seek to 'adopt the roles of social worker, psychologist, police, or priest'.

Dr Allister proclaims the mission of general practice in evangelical, almost messianic terms: we are GPs; gatekeepers to all the specialist treatments the NHS has to offer; and called to know, love, and care for people in the context in which they find themselves, at every stage in their lives.' The notion that doctors are 'called' to their medical mission implies some sort of a divine summons to their good work of saving bodies (improving health), and souls (enhancing wellbeing). But doctors are paid professionals who are consulted by patients who seek the benefit of their expertise and experience, they have no mandate to extend their interventions into patients' intimate personal and spiritual lives.

The idea that doctors have a duty to 'know, love, and care' for their patients reflects a confusion between the professional duty of a doctor to provide medical services and the responsibilities of a parent, a family caregiver, or a lover in an intimate personal relationship. This conflation of the personal and the professional, and the implicit collapse of the boundary between the private and the public spheres, carries a heavy cost for both doctor and patient. For the doctor, a certain distance, a respect for the privacy, and autonomy of the patient, is essential to the provision of dispassionate assessment and advice, and appropriate treatment. The patient should be able turn to their doctor for a degree of objectivity that they would not expect, or even welcome, from their close relatives and friends.

Dr Allister's mission statement reveals the intrusion of a baleful sentimentality into medical practice. It approves the expression of an inappropriate degree of affection in relations between doctors and patients: an excess of feeling that is, in reality, likely to be superficial and false. The inherent insincerity of the posture of the loving, caring doctor proposed by $\mathrm{Dr}$ Allister is exposed in the wider roles for general practice that she upholds. The touchy-feely GP is also the hard-nosed 'gatekeeper' to secondary care. The GP as commissioner regards the patient not as a person in need, but as a demanding consumer to be managed and contained. The GP as child protection police officer is invited to 'think dirty' and to regard all parents as potential abusers and all children as 'at risk'

The GP as agent of the new public health is encouraged to regard the patient as a mere unit of population, requiring nudging or nannying into approved healthy behaviours. In all these roles GPs are advised to take advantage of their intimate knowledge of patients and their families to facilitate surveillance and regulation.

Michael Fitzpatrick,

Barton House Health Centre, London, N16 9JT. E-mail: fitzleasynet.co.uk

\section{REFERENCES}

1. Lang D. How to protect general practice from child protection. Br J Gen Pract 2011; 61(587): 380.
2. Allister J. How to protect general practice from child protection. Br J Gen Pract 2011; 61(586): 326.

3. Fitzpatrick M. How to protect general practice from child protection. Br J Gen Pract 2011; 61(585): 299.

DOI: 10.3399/bjgp11X583010

\section{HIV: low prevalence is no excuse for not testing}

The article on HIV testing provides a compelling argument for identifying highrisk patients and attempting to diagnose HIV infection early. ${ }^{1}$ It provided an impetus to review the recorded HIV status of patients from countries of high HIV prevalence in our practice, and we searched and identified 124 patients born in sub-Saharan African countries. Among these, there are a variety of ages and ethnic groups. For the vast majority of these, no HIV status is recorded.

In your editorial, based on 2008 UK National Guidelines for HIV testing, HIV testing should be routinely offered to people from countries of high HIV prevalence. However, no further guidance is offered regarding if we should attempt to contact these patients systematically and, if so, how we should contact them. Clearly the language used in such a communication would be important given the stigma still associated with HIV. Opportunistic testing is an option, but given that some of these patients have not consulted for a number of years could mean that some time could pass before there is an opportunity to discuss HIV testing with the potential for delayed diagnosis.

Could the authors provide some guidance on the next steps we could take having identified a patient from high-risk countries with unknown HIV status?

Chris Smith,

GP \& NIHR In-Practice Fellow, Imperial College London, 46 Carlton House, Western Parade, Southsea, Hampshire, P05 3ED. E-mail: c.smithdimperial.ac.uk

\section{REFERENCE}

1. Arkell P, Stewart E, Williams I. HIV: low prevalence 